\title{
Effect of Substituents at Imide Positions on the Laser Performance of 1,7-Bay-Substituted Perylenediimide Dyes
}

\author{
Rafael Muñoz-Mármol,* Pedro G. Boj, José M. Villalvilla, José A. Quintana, Nathalie Zink-Lorre, \\ Ángela Sastre-Santos, Juan Aragó, Enrique Ortí, Paulius Baronas, Džiugas Litvinas, Saulius Juršènas, \\ Fernando Fenández-Lázaro,* and María A. Díaz-García*
}

Cite This: J. Phys. Chem. C 2021, 125, 12277-12288

Read Online

\section{ACCESS \\ WIII Metrics \& More \\ Article Recommendations \\ Supporting Information}

ABSTRACT: Perylenediimide (PDI) compounds with no substituents in their core are widely used as the active units of thin-film organic lasers. Recently, baysubstituted PDIs ( $b$-PDIs) bearing two sterically hindering diphenylphenoxy groups at the 1,7-bay positions have received great attention because they show red-shifted emission with respect to bay-unsubstituted PDIs, while maintaining high photoluminescence (PL) quantum yields and low amplified spontaneous emission (ASE) thresholds even at high doping rates. However, their ASE photostability is relatively low compared to that of state-of-the-art PDIs. Thus, the design of $b$-PDIs with improved ASE photostability remains a challenge. Here, the

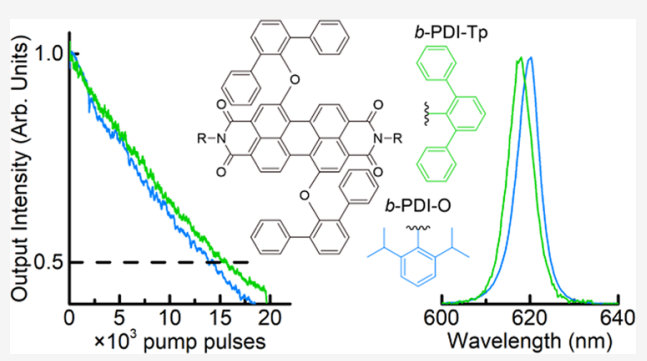
synthesis of two $b$-PDIs with phenyl-type substituents at the imide positions is reported. Complete characterization of their optical properties, including absorption, PL, ASE, and transient spectroscopy, supported also by quantum chemical calculations, is performed with the dyes diluted in either a liquid solvent or a polystyrene film. Film experiments were accomplished at very low doping rates, to resemble the isolated molecule behavior, and also in a range of increasing doping rates, to investigate concentration quenching effects. The reported $b$-PDIs show improved ASE photostability (3fold) with respect to $b$-PDIs with aliphatic-type substituents at the imide positions, whilst they show more propensity toward aggregation.

\section{INTRODUCTION}

Organic materials have been demonstrated to be suitable media for laser applications. ${ }^{1,2}$ Particularly, the large oscillator strength of electronic transitions associated with the excitation of $\pi$-electrons, the adoption of solution-based methods for lowcost integration with other technologies, ${ }^{3}$ and the lower toxicity of organic materials compared to their inorganic counterparts ${ }^{4}$ make them attractive for practical applications. ${ }^{5,6}$ In addition, the bottom-up synthesis techniques used in organic chemistry allow for fine control of the optoelectronic properties of the organic materials through the design of the molecular structure. ${ }^{7}$ Nonetheless, major challenges in device implementation remain unsolved, e.g., low pump requirements and/or long operational photostabilities.

Perylenediimides (PDIs) have been widely investigated as laser materials. In early works, PDI derivatives were studied in liquid solution as active materials for dye lasers. ${ }^{8,9}$ Soon after, PDIs were dispersed in polymer matrixes in monolithic form, pursuing improvements in compactness and maintenance. ${ }^{10,11}$ However, these solid-state lasers still showed the high operational energy requirements of their predecessors and resulted in additional photostability issues. In the literature, different synthetic strategies have been developed to improve the properties of PDIs toward lowering the optical pump energy needed (i.e., the threshold) for amplified spontaneous emission (ASE) and laser operation, and to tune the emission wavelength of PDIs. In a first step, substitution at the imide positions, leaving the bay positions of the perylene core unsubstituted (i.e., bay-unsubstituted or $u$-PDIs), intended to improve PDI solubility and increase the amount of PDI that could be incorporated into the polymer matrix without significant photoluminescence (PL) quenching. ${ }^{12-14}$ Following this strategy, the best results in terms of energy threshold were obtained for a 2,6-diisopropylphenyl-substituted PDI (PDI-O) dispersed in a polystyrene (PS) matrix at 1 wt \% (with a 2-3 $\mathrm{kW} \mathrm{cm}^{-2}$ threshold). ${ }^{12}$ Even so, for concentrations typically above $\sim 1$ wt $\%$, molecular interactions/aggregates appear, thus leading to concentration-induced quenching and the associated reduction of the emission efficiency. ${ }^{12,15-17}$ Moreover, the absorption and emission spectra of these derivatives remain unchanged with respect to that of the unsubstituted PDI core because of the electronic nodal character of the imide nitrogens. ${ }^{7}$ This constitutes a handicap since it limits the

Received: January 29, 2021

Revised: April 29, 2021

Published: May 28, 2021 


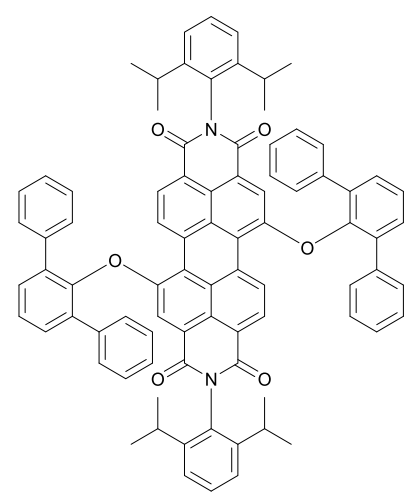

b-PDI-O

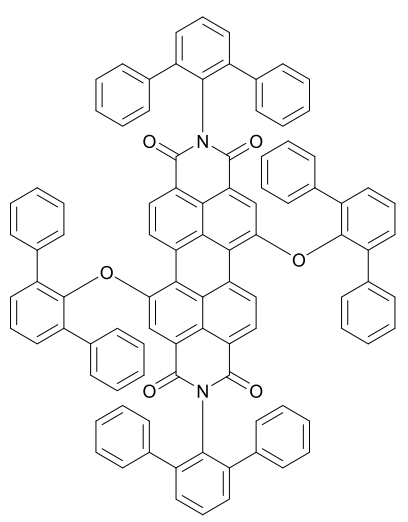

b-PDI-Tp

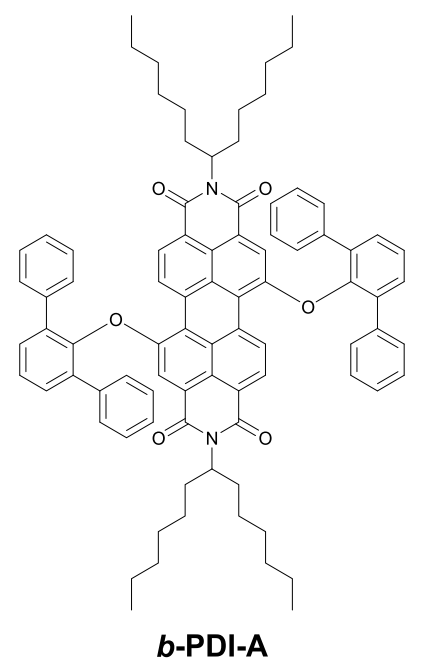

b-PDI-A

Figure 1. Chemical structures of $b$-PDI derivatives investigated: $b$-PDI-O, $b$-PDI-Tp, and $b$-PDI-A.

range of applications for these PDIs. Initial attempts of color tuning by substitution at the bay positions ${ }^{18-20}$ yielded PDI derivatives with poor emission efficiency, as a consequence of their distorted PDI core. ${ }^{18,19}$ This issue was solved by the introduction of diphenylphenoxy groups at the 1,7-bay positions of the PDI core ( $b$-PDIs). ${ }^{21-23}$ Such groups redshifted the absorption and emission spectra of the PDI with moderate distortion of the PDI core. Additionally, the substituents at the PDI core prevent molecular aggregation by steric hindrance, and they could be incorporated in the polymer matrix up to concentrations of around $30 \mathrm{wt} \%$ of PDI with respect to PS, with moderate concentration quenching. ${ }^{15,22,24}$ Despite the attractive features of these $b$-PDIs, a limitation is that the photostability of the compounds used so far is lower than that of state-of-the-art PDIs (i.e., u-PDIs), such as PDI-O. For example, PDI-O $\left(\tau_{1 / 2}{ }^{\text {ASE }} \sim 23000\right.$ pump pulses $)^{12}$ has been reported to be up to 6-7 times more photostable than $b$-PDI- $1\left(\tau_{1 / 2}{ }^{\text {ASE }} \sim 3600 \text { pump pulses }\right)^{22}$ under similar conditions, i.e., same pump intensity (2500 kW $\left.\mathrm{cm}^{-2}\right)$ and concentration in a PS matrix $\left(0.5 \mathrm{~mol} \mathrm{~g}^{-1}\right)$. Thus, the design of $b$-PDIs with improved photostability remains a challenge.

Here, we report the synthesis of two new $b$-PDIs with 2,6diisopropylphenyl and 2,6-diphenylphenyl (2,6-terphenyl) substituents at the imide positions (named $b$-PDI-O and $b$ PDI-Tp, respectively, chemical structures are shown in Figure 1 ), and complete characterization of their optical properties when dispersed in PS films, supported by quantum chemical calculations of isolated molecules and dimers. Comparisons are made with a previously reported $b$-PDI ( $b$-PDI-A in Figure 1$)$ with aliphatic chains at the imide positions. ${ }^{15}$ The investigated optical properties include absorption (ABS), PL, ASE (with a major focus on photostability), transient absorption, and timeresolved photoluminescence. The study has been conducted first on highly diluted films (dye concentrations of $0.8 \times 10^{-5}$ $\mathrm{mol} \mathrm{g}^{-1}$ in a PS matrix), for which dye aggregation/interaction effects are expected to be very small, thus approaching the behavior of isolated molecules. For a better assessment of this aspect, results are compared to measurements in liquid solution. Then, the effect on the optical performance by increasing the dye-doping ratio in the films has been investigated, to ascertain the role of the groups at the imide position in the appearance of molecular aggregation/ interaction.

\section{METHODS}

2.1. Synthesis. Solvents and reagents were obtained from commercial sources and used as received. Column chromatography: $\mathrm{SiO}_{2}(40-63 \mu \mathrm{m})$. TLC plates coated with $\mathrm{SiO}_{2}$ $60 F 254$ were visualized by UV light. NMR spectra were recorded at $25{ }^{\circ} \mathrm{C}$ using a Bruker AC300 spectrometer. The solvents for spectroscopic studies were of spectroscopy grade and used as received. UV/vis spectra were measured with a Helios $\Gamma$ spectrophotometer. IR spectra were recorded with a Nicolet Impact 400D spectrophotometer. High-resolution mass spectra were obtained from a Bruker Reflex II matrixassisted laser desorption/ionization time-of-flight (MALDITOF) spectrometer using dithranol as the matrix.

2.1.1. Synthesis of b-PDI-O. A mixture of $1,7-\mathrm{bis}\left(2^{\prime}, 6^{\prime}\right.$ diphenylphenoxy)perylene-3,4,9,10-tetracarboxylic dianhydride (100 mg, $0.11 \mathrm{mmol}), 2,6$-diisopropylaniline $(120 \mathrm{mg}$, $0.68 \mathrm{mmol})$, zinc acetate $(16 \mathrm{mg}, 0.08 \mathrm{mmol})$, and distilled quinoline $(0.8 \mathrm{~mL})$ was heated for $24 \mathrm{~h}$ at $220{ }^{\circ} \mathrm{C}$ under an argon atmosphere and, after cooling, the residue was washed with a mixture of methanol/water (3:1). Purification was carried out by silica gel column chromatography using $\mathrm{CH}_{2} \mathrm{Cl}_{2}$ as the eluent, yielding $60 \mathrm{mg}(45 \%)$ of a pink powder.

- ${ }^{1} \mathrm{H}$ NMR (300 MHz, $\mathrm{CDCl}_{3}$ ), $\delta: 9.22$ (d, $J=8.38 \mathrm{~Hz}$, $2 \mathrm{H}), 8.44(\mathrm{~d}, J=8.38 \mathrm{~Hz}, 2 \mathrm{H}), 8.05(\mathrm{~s}, 2 \mathrm{H}), 7.51-7.33$ $(\mathrm{m}, 20 \mathrm{H}), 7.05(\mathrm{~m}, 12 \mathrm{H}), 2.67$ (sept, $J=6.74 \mathrm{~Hz}, 4 \mathrm{H})$, $1.18-1.26(\mathrm{~m}, 24 \mathrm{H}) \mathrm{ppm}$.

- ${ }^{13} \mathrm{C}$ NMR (75 $\mathrm{MHz} \mathrm{CDCl}_{3}$ ), $\delta: 166.4,166.2,158.2$, $150.8,148.7,140.6,139.1,136.4,134.3,134.0,132.5$, $132.4,132.1,132.0,131.7,130.9,130.4,129.8,127.4$, 127.0, 125.7, 124.6, 124.6, 123.4, 32.2, 27.0 ppm.

- Fourier transform infrared (FT-IR) (KBr), $\nu$ : 3037, 2914, 2815, 1706, 1654, 1590, 1339, 761, $708 \mathrm{~cm}^{-1}$.

- UV/vis $\left(\mathrm{CH}_{2} \mathrm{Cl}_{2}\right), \lambda_{\max }(\log \varepsilon): 398$ (3.9), 488 (4.1), 521 (4.6), $562(4.8) \mathrm{nm}$.

- MS (MALDI-TOF), $m / z$ : calcd for $\mathrm{C}_{84} \mathrm{H}_{66} \mathrm{~N}_{2} \mathrm{O}_{6}$ $1198.4921\left[\mathrm{M}^{-}\right]$found $1198.4548\left[\mathrm{M}^{-}\right]$.

2.1.2. Synthesis of b-PDI-Tp. A mixture of $1,7-\mathrm{bis}\left(2^{\prime}, 6^{\prime}-\right.$ diphenylphenoxy)perylene-3,4,9,10-tetracarboxylic dianhydride (100 mg, $0.11 \mathrm{mmol}$ ), 2,6-diphenylaniline (166 mg, 
$0.68 \mathrm{mmol})$, zinc acetate $(16 \mathrm{mg}, 0.08 \mathrm{mmol})$, and distilled quinoline $(0.8 \mathrm{~mL})$ was heated for $24 \mathrm{~h}$ at $220^{\circ} \mathrm{C}$ under an argon atmosphere and, after cooling, the residue was washed with a mixture of methanol/water (3:1). Purification was carried out by silica gel column chromatography using $\mathrm{CH}_{2} \mathrm{Cl}_{2}$ as eluent, yielding $71 \mathrm{mg}$ (48\%) of a pink powder.

- ${ }^{1} \mathrm{H}$ NMR (300 MHz, $\mathrm{CDCl}_{3}$ ), $\delta: 8.96(\mathrm{~d}, J=8.34 \mathrm{~Hz}$, $2 \mathrm{H}), 8.23(\mathrm{~d}, J=8.34 \mathrm{~Hz}, 2 \mathrm{H}), 7.67(\mathrm{~s}, 2 \mathrm{H}), 7.60(\mathrm{~m}$, $2 \mathrm{H}), 7.49-7.45(\mathrm{~m}, 10 \mathrm{H}), 7.32-7.29(\mathrm{~m}, 8 \mathrm{H}), 7.19-$ $7.13(\mathrm{~m}, 20 \mathrm{H}), 6.81(\mathrm{~m}, 12 \mathrm{H}) \mathrm{ppm}$.

- ${ }^{13} \mathrm{C}$ NMR (75 MHz $\left.\mathrm{CDCl}_{3}\right), \delta: 163.6,163.0,154.9$, $148.1,141.6,139.2,137.3,136.1,133.0,131.2,131.1$, $130.1,129.0,129.0,128.9,128.4,128.3,128.2,127.8$, $127.7,127.2,127.2,126.4,123.7,122.0,121.6,120.6$, $120.3 \mathrm{ppm}$.

- FT-IR (KBr), $\nu$ : 3049, 2909, 2833, 1695, 1666, 1596, 1497, 1398, 1334, 1246, 1164, 913, 762, $703 \mathrm{~cm}^{-1}$.

- $\mathrm{UV} /$ vis $\left(\mathrm{CH}_{2} \mathrm{Cl}_{2}\right), \lambda_{\max }(\log \varepsilon): 406$ (3.9), 485 (4.2), 520 (4.6), 561 (4.8) $\mathrm{nm}$.

- MS (MALDI-TOF), $m / z$ : calcd for $\mathrm{C}_{96} \mathrm{H}_{58} \mathrm{~N}_{2} \mathrm{O}_{6}$ $1334.4289\left[\mathrm{M}^{-}\right]$, found $1334.4672\left[\mathrm{M}^{-}\right]$.

2.2. Quantum Chemical Calculations. Density functional theory (DFT) calculations using the B3LYP functional, ${ }^{25,26}$ with the latest Grimme's dispersion correction $\mathrm{D} 3^{27}$ and the $6-31 \mathrm{G}^{* *}$ basis set, ${ }^{28}$ were carried out using the Gaussian 16 (revision A.03) software package. ${ }^{29}$ No symmetry constraints were applied during geometry optimizations. Vertical electronic transition energies to the lowest-energy singlet excited states of $b$-PDI-A, $b$-PDI-O, and $b$-PDI-Tp were computed using the time-dependent DFT (TD-DFT) approach. $^{30-32}$ The lowest 50 singlet excited states were calculated at the B3LYP/6-31G** level using the ground-state optimized geometries. Molecular orbitals were plotted using ChemCraft 1.6 software with isovalue contours of $\pm 0.03 \mathrm{au}^{33}$ Calculations using the semiempirical tight-binding (GFN2xTB) $\operatorname{method}^{34}$ were performed using the xTB program recently developed by Grimme and co-workers. ${ }^{35}$

2.3. Thin Film Fabrication. PS thin films doped with a $b$ PDI derivative (among the ones investigated, see Figure 1) were prepared by spin-coating a dichloromethane solution of the polymer and the corresponding $b$-PDI on top of a quartz substrate. The dye concentration in the film was calculated as the amount of $b$-PDI with respect to PS in the solution. For the first part of this work, highly diluted dye-doped films were prepared (the $b$-PDI doping rate was $0.8 \times 10^{-5} \mathrm{~mol} \mathrm{~g}^{-1}$, approximately 1 wt \%). In the second part of the work, dedicated to investigate the concentration dependence, the doping rate was varied between $0.8 \times 10^{-5}$ and $1 \times 10^{-4} \mathrm{~mol}$ $\mathrm{g}^{-1}$ (approximately between 1 and 11 wt \%). For all of the films prepared, the amount of PS with respect to the solvent was adjusted to obtain a film thickness $\left(h_{\mathrm{f}}\right)$ of around $550 \mathrm{~nm}$. This guarantees that the films support only fundamental transversal waveguide modes $\left(\mathrm{TE}_{0}\right.$ and $\left.\mathrm{TM}_{0}\right)$ with a high confinement factor $(\Gamma \approx 90 \%)$. After deposition, the films were heated for $2 \mathrm{~h}$ at $90{ }^{\circ} \mathrm{C}$ to remove any residual solvent. Film thickness was measured using an interferometric technique. ${ }^{36}$

2.4. Optical Characterization. Steady-state ABS and PL measurements were recorded in a Jasco V-650 spectrometer and a Jasco FP-6500/6600 fluorimeter, respectively. For experiments in liquid solution (toluene, $1 \times 10^{-6} \mathrm{M}$ ), a 10 $\mathrm{mm}$ quartz cell was used. The extinction coefficient $(\varepsilon)$ was determined from the absorbance $(A)$ using the expression $\varepsilon=$
$A / l \cdot C$, with $l$ the light path length of the sample and $C$ the dye concentration. For films, the absorption coefficient $(\alpha)$ was calculated through the expression $\alpha=\ln (10) \cdot A / h_{\mathrm{f}}$, where $h_{\mathrm{f}}$ is the film thickness.

The PL efficiency in solution $\left(\phi_{\mathrm{PL}}{ }^{\mathrm{sol}}\right)$ was determined by a comparative method, ${ }^{37}$ using two well-established references, $N, N^{\prime}$-di( $1^{\prime}$-hexylheptyl)perylene-3,4:9,10-tetracarboxylic diimide $\left(\phi_{\mathrm{PL}}{ }^{\text {sol }}=99 \% \text { in DCM }\right)^{38}$ and rhodamine $6 \mathrm{G}\left(\phi_{\mathrm{PL}}{ }^{\text {sol }}=\right.$ $94 \%$ in ethanol). ${ }^{39}$ The PL quantum yield in the films $\left(\phi_{\mathrm{PL}}\right.$ film $)$ was determined using an integrating sphere attached to the fluorimeter.

Photoluminescence transients in both solution and thin film were collected at $\lambda=575 \mathrm{~nm}$, coinciding with the main PL transition (0-0), using a time-correlated single-photon counting (TCSPC) system PicoHarp 300 (PicoQuant $\mathrm{GmbH}$ ) and a semiconductor diode laser (1 MHz, $70 \mathrm{ps,}$ $510 \mathrm{~nm}$ ) as the excitation source. Data were fitted to single, double, or triple exponential functions, as required, and the average PL lifetimes $\left(\tau_{\mathrm{PL}}\right)$ were determined by the expression ${ }^{40}$

$$
\tau_{\mathrm{PL}}=\frac{\sum A_{i} \tau_{i}}{\sum A_{i}}
$$

where $\tau_{i}$ are the time constants of the exponential functions used in the fitting and $A_{i}$ their corresponding weights.

The ASE properties of the film samples were investigated using the second harmonic of an Nd:YAG laser $(532 \mathrm{~nm}, 10$ $\mathrm{ns}, 10 \mathrm{~Hz}$ ) as the pumping source. A detailed description of the setup can be found elsewhere. ${ }^{12,41}$ The excitation laser beam was expanded and collimated, and the uniform central part was selected. Then, it was shaped into a narrow stripe of $3.5 \mathrm{~mm}$ by $0.5 \mathrm{~mm}$, by means of a cylindrical lens and an adjustable slit, and the image of the slit was projected onto the sample in contact with its edge. The impinging energy was controlled using neutral density filters and the emitted PL was collected from the film edge with an Ocean Optics USB2000-UV-VIS fiber spectrometer with $1.3 \mathrm{~nm}$ spectral resolution. The presence of ASE is detected by a narrowing of the emitted spectrum, accompanied by a sudden increase of the output intensity $\left(I_{\text {out }}\right)$, at a certain pump intensity (the ASE threshold, $\left.I_{\text {th }}{ }^{\text {ASE }}\right)$. The ASE photostability was studied by following the temporal evolution of the emitted ASE light (well above the threshold) for uninterrupted pump excitation, under ambient conditions, at the same spot of the sample. It was quantitatively characterized through the ASE photostability half-life $\left(\tau_{1 / 2}{ }^{\mathrm{ASE}}\right)$, defined as the time (or the number of pump pulses) at which the ASE intensity reaches half of its initial value.

Femtosecond time-resolved differential transient absorption (TA) measurements were performed with a Harpia pumpprobe spectrometer, pumped with a Yr:KGW pulsed laser Pharos-SP $(1030 \mathrm{~nm}, 200 \mathrm{fs}, 10 \mathrm{kHz})$ coupled to an optical parametric amplifier Orpheus (commercial Light Conversion system). The pump-beam wavelength was set to $520 \mathrm{~nm}$ (coinciding with the second vibronic absorption peak). The probe white-light continuum pulse was generated by focusing the fundamental onto a sapphire crystal. The time delay between pump and probe was controlled with a retroreflector on a delay line. Both beams were spatially crossed in the sample and the differential absorption spectra $(\Delta A)$ defined as $\Delta A=-\log (\Delta T)$, with $\Delta T$ being the difference in transmittance with and without the pump pulse. The stimulated emission $(\mathrm{SE})$ cross-section $\left(\sigma_{\mathrm{SE}}\right)$ was estimated from the 
Scheme 1. Synthesis of $b$-PDI-O and $b$-PDI-Tp
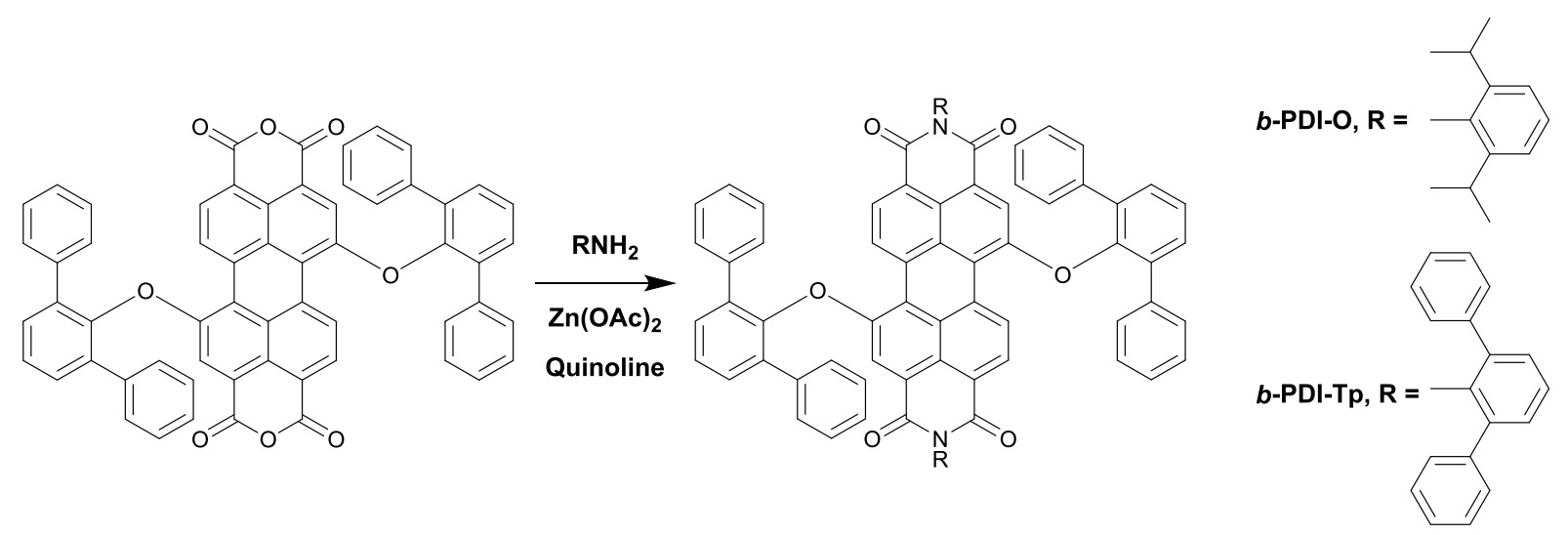

(a)

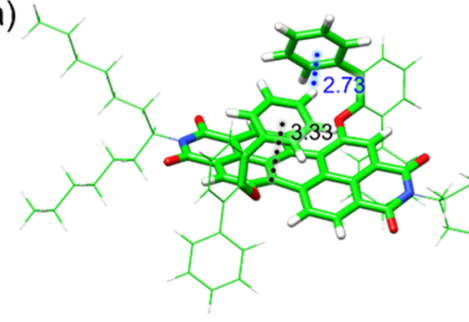

(b)

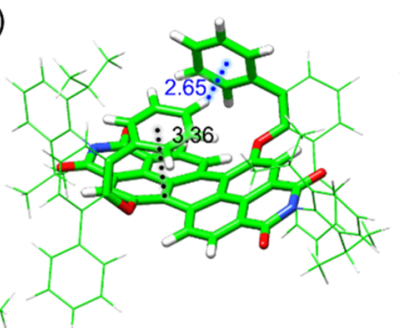

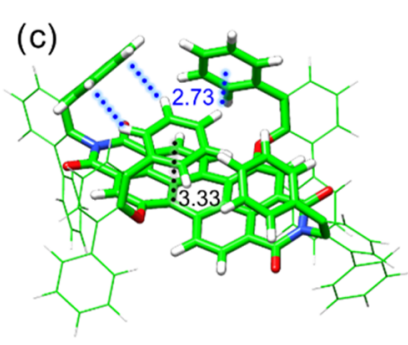

Figure 2. B3LYP-D3/6-31G**-optimized geometries calculated for $b$-PDI-A (a), $b$-PDI-O (b), and $b$-PDI-Tp (c). Short $\pi-\pi$ and C-H $\cdots \pi$ contacts, in $\AA$, are highlighted with black and blue dotted lines, respectively.

transient at the SE peak, by taking its maximum $|\Delta A|$ and using the following expression ${ }^{42}$

$$
\begin{aligned}
& \sigma_{\mathrm{SE}}=-\frac{|\Delta A|}{h_{\mathrm{f}} \cdot N_{0}} \ln 10 \\
& N_{0}=\frac{\lambda I_{0}}{h c \cdot h_{\mathrm{f}}}\left(1-e^{-\alpha \cdot h_{\mathrm{f}}}\right)(1-R)
\end{aligned}
$$

where $N_{0}$ is the excited-state population density in the sample, $R$ is the sample reflectance ( $\approx 11 \%), h$ is the Planck constant, $c$ is the speed of light, $\lambda$ is the excitation wavelength, $\alpha$ is the absorption coefficient at $\lambda, h_{\mathrm{f}}$ is the film thickness, and $I_{0}$ is the excitation fluence.

\section{RESULTS AND DISCUSSION}

3.1. Synthesis. Compound b-PDI-A was synthesized following the previously reported procedure. ${ }^{15}$ Compounds $b$-PDI-O and $b$-PDI-Tp were synthesized by the condensation reaction, described above in the Section 2, between perylenetetracarboxylic dianhydride and the corresponding amine, namely 2,6-diisopropylaniline and 2,6-diphenylaniline, in 45 and $48 \%$ yield, respectively (Scheme 1). Both compounds were characterized by ${ }^{1} \mathrm{H},{ }^{13} \mathrm{C}$ NMR (Figures $\mathrm{S} 1$ and S2) and FT-IR spectroscopy, and MALDI-TOF MS (Figure S3).

3.2. Theoretical Calculations. Prior to analyzing the experimental optical properties (see below), the structural properties of the bay-substituted $b$-PDI derivatives were studied from a computational perspective by means of density functional theory (DFT) and semiempirical (GFN2-xTB) calculations. Figure 2 displays the minimum-energy optimized structures calculated for $b$-PDI-A, $b$-PDI-O, and $b$-PDI-Tp at the B3LYP-D3/6-31G** level. The three $b$-PDI derivatives exhibit PDI cores slightly distorted from planarity due to the diphenylphenoxy groups attached to the 1,7-bay positions. The angle formed by the average planes, defined by the two naphthaleneimide units forming the PDI core, is $19.2^{\circ}$ for $b$ PDI-A and slightly increases to 24.5 and $23.7^{\circ}$ for $b$-PDI-O and $b$-PDI-Tp, respectively. Note that the respective PDIs calculated without anchoring the diphenylphenoxy groups to bay positions display planar PDI cores (angles of around $0^{\circ}$ ). For the three $b$-PDIs, one of the diphenylphenoxy groups is oriented in such a way that a $\pi$-stacking between a benzene ring of the substituent and the PDI core is effectively established with distances in the 3.35-3.40 $\AA$ range. Apart from the $\pi-\pi$ interactions, the diphenylphenoxy groups are able to interact among themselves by $\mathrm{C}-\mathrm{H} \cdots \pi$ interactions at distances of around 2.6-2.7 $\AA$. For the $b$-PDI-Tp compound, $\mathrm{C}-\mathrm{H} \cdots \pi$ interactions are also present between the bulky $m$ terphenyl groups at the imide positions and the phenyl rings of the bay substituents (Figure 2c). Note that the intramolecular arrangement predicted for the three $b$-PDI compounds completely protects one face of the $b$-PDI core, which may in principle hinder molecular aggregation.

To explore the potential self-assembly of the $b$-PDI derivatives, supramolecular dimers based on the previously DFT-optimized molecular structures of the monomers were built with different arrangements and optimized at the semiempirical GFN2-xTB level. Figure S4 displays the optimized structures calculated for three representative supramolecular dimers of $b$-PDI-A (dA-1, dA-2, and dA-3). Dimer $\mathrm{dA}-1$ is governed, despite the bulky groups at the bay positions, by effective $\pi-\pi$ interactions between the $b$-PDI cores through the PDI faces that are not covered by the diphenylphenoxy groups (centroid-centroid distance of $3.31 \AA$ ). In dimer dA-2, the $b$-PDI-A molecules self-assemble in a co-facial arrangement with the distance between the PDI centroids as long as $8.92 \AA$ 

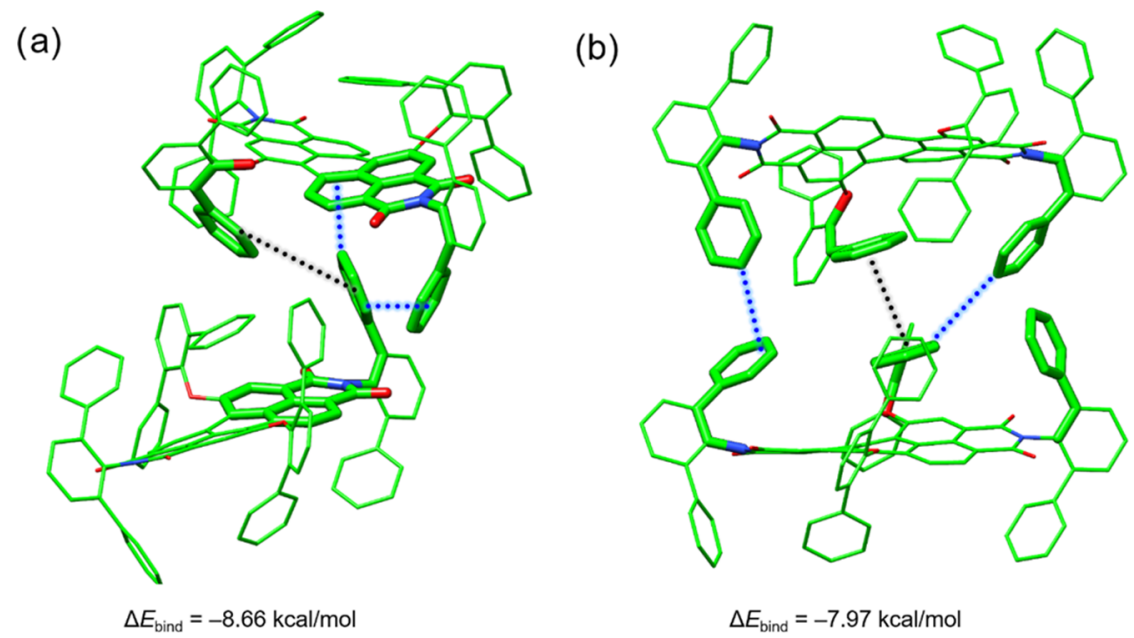

Figure 3. GFN2-xTB-optimized structures calculated for supramolecular dimers dTp-1 (a) and dTp-2 (b) of $b$-PDI-Tp. Short $\pi-\pi$ and C-H $\cdots \pi$ contacts are highlighted with black and blue dotted lines, respectively. Hydrogen atoms are omitted for clarity.

Table 1. Photophysical Parameters for $b$-PDIs in Toluene Solution and in PS-Doped Films

\begin{tabular}{|c|c|c|c|c|c|c|c|c|c|c|}
\hline dye & sample & dye conc. & $\lambda_{\mathrm{ABS}}{ }^{b}$ & $\lambda_{\mathrm{PL}}{ }^{c}$ & $\phi_{\mathrm{PL}}{ }^{d}$ & $\tau_{\mathrm{PL}}{ }^{e}$ & $\alpha\left(\text { at } \lambda_{\text {pump }}\right)^{f}$ & $\lambda_{\mathrm{ASE}}{ }^{g}$ & $I_{\mathrm{th}}^{\mathrm{ASE} h}$ & $\tau_{1 / 2}{ }^{\mathrm{ASE} i}$ \\
\hline & & $\overline{\times 10^{-5} \mathrm{~mol} \mathrm{~g}^{-1}(\mathrm{wt} \%)}$ & $\mathrm{nm}$ & $\mathrm{nm}$ & $\%$ & ns & $\overline{\times 10^{4} \mathrm{~cm}^{-1}}$ & $\mathrm{~nm}$ & $\overline{\mathrm{kW} \mathrm{cm}} \mathrm{cm}^{-2}$ & $\overline{\times 10^{3} \text { pulses }(\mathrm{min})}$ \\
\hline \multirow[t]{4}{*}{$b$-PDI-O } & solution & $a$ & $485 / 518 / \underline{558}$ & $\underline{576} / 618$ & $89 \pm 5$ & 4.9 & & & & \\
\hline & film & $0.80(1.0)$ & $487 / 520 / \underline{560}$ & $\underline{575} / 617$ & $87 \pm 6$ & 5.1 & 0.05 & 620.3 & 60 & $14(23)$ \\
\hline & film & $5.00(5.7)$ & $487 / 520 / 560$ & $579 / 619$ & $42 \pm 3$ & 3.0 & 0.29 & 623.5 & 50 & $4.8(8)$ \\
\hline & film & $10.0(10.7)$ & $487 / 520 / \underline{\underline{560}}$ & $\underline{\underline{580}} / 620$ & $21 \pm 3$ & 1.4 & 0.54 & 624.5 & 55 & $0.6(1)$ \\
\hline \multirow[t]{4}{*}{$b$-PDI-Tp } & solution & a & $487 / 519 / \underline{558}$ & $\underline{574} / 616$ & $78 \pm 5$ & 5.1 & & & & \\
\hline & film & $1.00(1.3)$ & $487 / 519 / \underline{559}$ & $\underline{570} / 616$ & $61 \pm 5$ & 4.2 & 0.06 & 617.8 & 230 & $16(27)$ \\
\hline & film & $5.00(6.7)$ & $487 / 519 / \underline{559}$ & $575 / \underline{620} / 670$ & $12 \pm 5$ & 0.5 & 0.29 & 620.6 & 430 & \\
\hline & film & $10.0(11.7)$ & $487 / 519 / \underline{559}$ & $579 / \underline{623} / 670$ & $2 \pm 5$ & 0.3 & 0.55 & & & \\
\hline \multirow[t]{4}{*}{$b$-PDI-A } & solution & $a$ & $484 / 517 / \underline{556}$ & $\underline{573} / 617$ & $92 \pm 5$ & 5.1 & & & & \\
\hline & film & $1.00(1.2)$ & $485 / 518 / \underline{558}$ & $\underline{572} / 617$ & $89 \pm 5$ & 5.6 & 0.06 & 617.7 & 40 & $5.4(9)$ \\
\hline & film & $5.00(5.9)$ & $485 / 518 / \underline{558}$ & $\overline{\underline{575}} / 618$ & $83 \pm 3$ & 6.3 & 0.26 & 621.2 & 8.5 & $1.2(2)$ \\
\hline & film & $10.0(11.1)$ & $485 / 518 / \overline{558}$ & $\underline{577} / 619$ & $78 \pm 3$ & 6.0 & 0.50 & 623.1 & 7.5 & $1.8(3)$ \\
\hline
\end{tabular}

${ }^{a} b$-PDI concentration in toluene solutions was $10^{-6} \mathrm{M} .{ }^{b}$ Peak absorption wavelengths (error $= \pm 1 \mathrm{~nm}$, maximum absorption peak is underlined). ${ }^{c}$ Peak photoluminescence wavelengths (error $= \pm 1 \mathrm{~nm}$, maximum emission peak is underlined). ${ }^{d}$ Photoluminescence quantum yield. ${ }^{e}$ Average fluorescence lifetime (error $\approx 5 \%) .{ }^{f}$ Absorption coefficient at $\lambda_{\text {pump }}\left(\right.$ error $= \pm 100 \mathrm{~cm}^{-1}$ ). ${ }^{g}$ Amplified spontaneous emission (ASE) wavelength (error $= \pm 0.7 \mathrm{~nm}) .{ }^{h}$ ASE threshold (error $\left.\approx 20 \%\right)$ measured at $\lambda_{\text {pump }}=532 \mathrm{~nm}$ from Nd:YAG second harmonic $(10 \mathrm{~Hz}$ and $10 \mathrm{~ns}) .{ }^{i}$ Photostability half-life measured under a permanent pulsed pump at $532 \mathrm{~nm}(10 \mathrm{~Hz}, 10 \mathrm{~nm})$ with $2500 \mathrm{~kW} \mathrm{~cm}^{-2}$ in the same spot and under ambient conditions $($ error $\approx 20 \%)$.

because up to three benzene rings of the bay substituents are intercalated (Figure S4b). Dimer dA-3 exhibits a perfect $\pi$ stacking arrangement where the two PDI cores, situated at a distance of $10.24 \AA$, are separated by a $\pi-\pi$ benzene dimer (centroid-centroid distance of $3.52 \AA$ ) formed by the diphenylphenoxy arms (Figure S4c). Among the three dimers, the face-to-face dimer (dA-1) turned out to be the most stable with a binding energy $\left(\Delta E_{\text {bind }}\right)$ of $-19.90 \mathrm{kcal} \mathrm{mol}^{-1}$ compared to dA-2 $\left(-11.90 \mathrm{kcal} \mathrm{mol}^{-1}\right)$ and dA-3 $\left(-7.27 \mathrm{kcal} \mathrm{mol}^{-1}\right)$. Nevertheless, under the experimental conditions (toluene solution), the formation of the face-to-face dimer dA-1 is especially unlikely because (1) solvent molecules easily solvate the accessible $b$-PDI $\pi$-surfaces and (2) the peripheral imide and bay groups have to largely accommodate their orientation to allow for the face-to-face interaction. For $b$-PDI-O, similar supramolecular dimers ( $\mathrm{dO}-1, \mathrm{dO}-2$ and $\mathrm{dO}-3)$ were obtained at GFN2-xTB (Figure S5).

In contrast to $b$-PDI-A and $b$-PDI-O, face-to-face supramolecular dimers in $b$-PDI-Tp are not favored because of the bulky groups at both the bay and imide positions. Nonetheless, a wide variety of self-assembling dimers, such as the dTp-1 and $\mathrm{dTp}-2$ dimers depicted in Figure 3, governed mainly by $\pi-\pi$ and $\mathrm{C}-\mathrm{H} \cdots \pi$ interactions between the diphenylphenoxy and the terphenyl substituent groups, are predicted for $b$-PDI-Tp. These dimers are easily formed because they imply no reorganization of the molecular geometry and are calculated to be stable with $\Delta E_{\text {bind }}$ values in the range between -8 and $-11 \mathrm{kcal} \mathrm{mol}^{-1}$. It should be stressed that dimers dTp-1 and $\mathrm{dTp}-2$, although less stable compared to the face-to-face dispositions for $b$-PDI-A (dA-1) and $b$-PDI-O (dO-1), are organized in such a way that they may even grow into larger supramolecular assemblies in contrast to the face-to-face dimers. These peculiar assemblies in $\mathrm{dTp}-1$ and $\mathrm{dTp}-2$, due to the large balance between $\pi-\pi$ and $\mathrm{C}-\mathrm{H} \cdots \pi$ interactions, suggest good ability of $b$-PDI-Tp to self-assemble and may explain why the $b$-PDI-Tp compound is, among the three $b$ PDI derivatives, the system with the smallest emission quantum yields both in solution and in doped thin films (see below). 

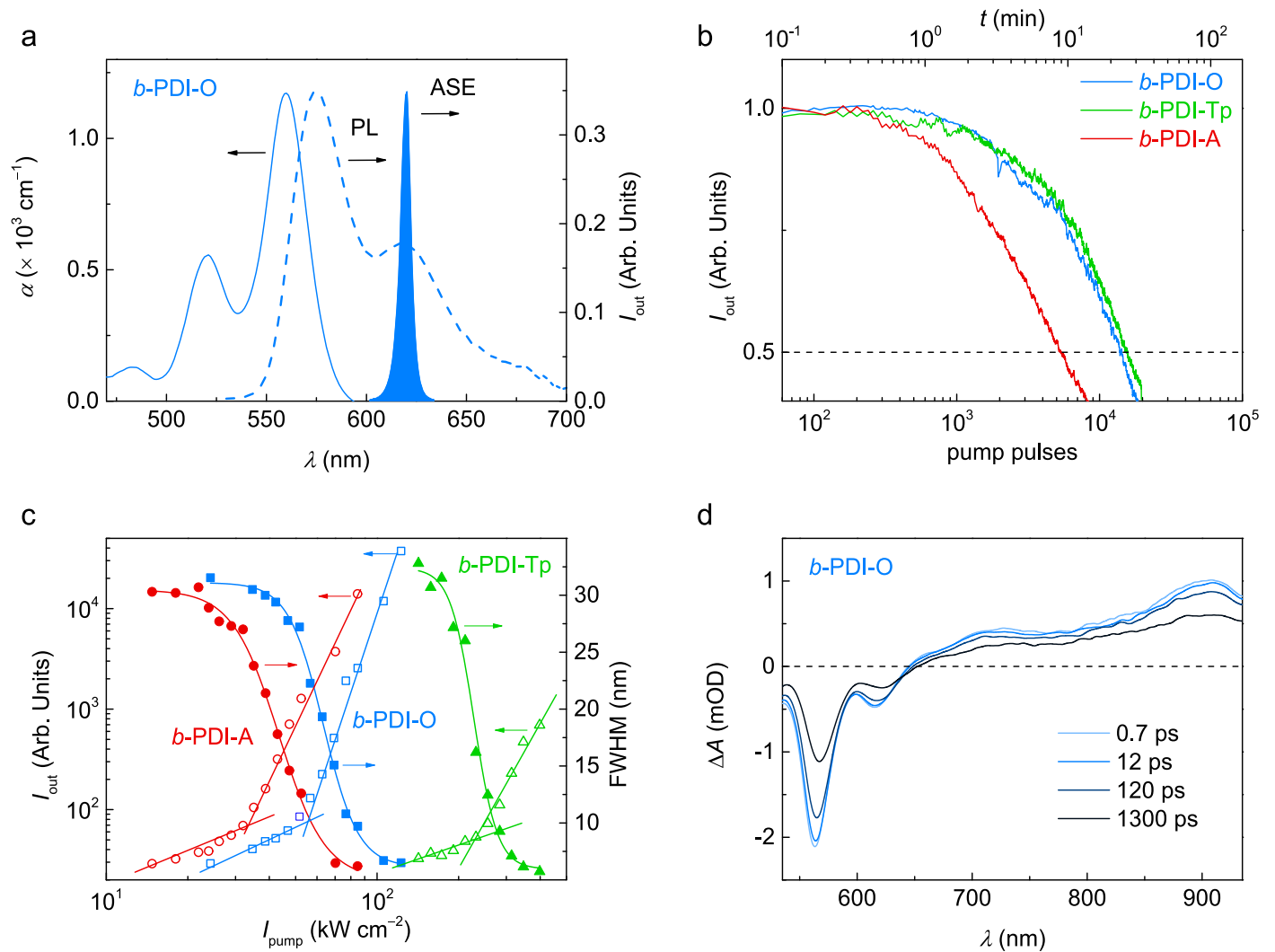

Figure 4. Optical properties of PS films doped with a low concentration of $b$-PDI. (a) Optical properties of PS films doped with $0.8 \times 10^{-5} \mathrm{~mol} \mathrm{~g}^{-1}$ of $b$-PDI-O. Absorption coefficient ( $\alpha$, solid line, left axis), photoluminescence intensity (PL, dashed line, right axis), and amplified spontaneous emission (ASE) intensity (filled area, right axis) versus wavelength, $\lambda$. (b) Normalized ASE intensity at ASE wavelength, $\lambda_{\text {ASE }}$ as a function of the number of pump pulses $\left(10 \mathrm{~ns}, 10 \mathrm{~Hz}\right.$ ) for PS films doped with $1 \times 10^{-5} \mathrm{~mol} \mathrm{~g}^{-1}$ of $b$-PDI-A (red line), $0.8 \times 10^{-5} \mathrm{~mol} \mathrm{~g}^{-1}$ of $b$-PDI-O (blue line), and $1 \times 10^{-5} \mathrm{~mol} \mathrm{~g}^{-1}$ of $b$-PDI-Tp (green line) under uninterrupted excitation at $2500 \mathrm{~kW} \mathrm{~cm}^{-2}$. (c) Output intensity at $\lambda_{\mathrm{ASE}}\left(I_{\text {out }}\right.$ open symbols, left axis) and linewidth (full width at half-maximum, FWHM, full symbols, right axis), as a function of pump intensity for PS films doped with $1 \times$ $10^{-5} \mathrm{~mol} \mathrm{~g}{ }^{-1}$ of $b$-PDI-A (red circles), $0.8 \times 10^{-5} \mathrm{~mol} \mathrm{~g}^{-1}$ of $b$-PDI-O (blue squares), and $1 \times 10^{-5} \mathrm{~mol} \mathrm{~g}^{-1}$ of $b$-PDI-Tp (green triangles). Lines are guides to the eye. (d) Differential absorption spectra at significant delay times $(\Delta A)$ for PS films doped with $0.8 \times 10^{-5}$ mol g ${ }^{-1}$ of $b$-PDI-O as a function of $\lambda$. The pump wavelength was set to $520 \mathrm{~nm}$.

3.3. Optical Properties in Liquid Solution. In liquid solution (toluene, $1 \times 10^{-6} \mathrm{M}$ ), the ABS and PL spectra of the three $b$-PDIs are very similar (see Figure S6). They present the typical vibronic progression for PDI derivatives, with $\mathrm{ABS}$ peaks at around 490, 520, and $560 \mathrm{~nm}$ and PL peaks at around 575 and $620 \mathrm{~nm}$ (see Table 1), and molar extinction coefficients $(\varepsilon)$ of around $60 \mathrm{mM}^{-1} \mathrm{~cm}^{-1}$. The low-lying singlet excited states were computed for the three $b$-PDI derivatives within the time-dependent DFT (TD-DFT) framework at the B3LYP-D3/6-31G** level. For $b$-PDI-A, $b$ PDI-O, and $b$-PDI-Tp compounds, the $S_{0} \rightarrow S_{1}$ electronic transitions are computed to appear at close wavelengths (552, 561 , and $559 \mathrm{~nm}$, respectively) and with similar oscillator strengths (Table S1) in good correlation with the experiment. The $S_{0} \rightarrow S_{1}$ transitions are of $\pi-\pi^{*}$ nature and are mainly described by the highest occupied molecular orbital (HOMO) $\rightarrow$ lowest unoccupied molecular orbital (LUMO) one-electron promotion localized on the $b$-PDI cores (Figure S7).

PL lifetimes, obtained from fits to single exponential functions, are also similar for the three compounds $\left(\tau_{\mathrm{PL}}{ }^{\text {sol }} \approx\right.$ $5 \mathrm{~ns}$; see Figure S8 and Table 1). Interestingly, slight differences are found in the PL efficiency among the three compounds (see details in the Supporting Information, Figure S9 and Table 1). Very large $\phi_{\mathrm{PL}}{ }^{\text {sol }}$ values have been measured for $b$-PDI-A and $b$-PDI-O (92 and 89\%, respectively), whereas a lower value was obtained for $b$-PDI-Tp $\left(\phi_{\mathrm{PL}}{ }^{\text {sol }}=78 \%\right)$. The decrease of the emission quantum yield cannot be in principle associated with the distortion from planarity of the PDI $\pi$ scaffold because, as discussed above, similar values of the angle defined by the two naphthaleneimide units forming the PDI core are predicted for the three derivatives $\left(19.2^{\circ}\right.$ for $b$-PDI-A, $24.5^{\circ}$ for $b$-PDI-O, and $23.7^{\circ}$ for $b$-PDI-Tp). Accordingly, the lower $\phi_{\mathrm{PL}}{ }^{\text {sol }}$ value found for $b$-PDI-Tp could be due to a large number of intramolecular interactions of the PDI core with the peripheral benzene rings (Figure 2c) and also due to the good ability of $b$-PDI-Tp to form supramolecular dimers (Figure 3). Both factors can contribute to quench the emission from the PDI core.

3.4. Highly Diluted Dye-Doped Films. 3.4.1. Absorbance and Photoluminescence. The ABS and PL spectra of the highly diluted films $\left(0.8 \times 10^{-5} \mathrm{~mol} \mathrm{~g}^{-1}\right.$ for $b$-PDI-O, Figure 4a, and $1 \times 10^{-5} \mathrm{~mol} \mathrm{~g}^{-1}$ for $b$-PDI-Tp and $b$-PDI-A, Figures S10 and S11) are similar to those obtained in solution, indicating that, at least for these properties, molecular interaction effects are not very significant. The vibronic progression in the ABS and PL bands observed in the spectra in liquid solution (Figure S6) are preserved in the films, with just slight shifts in the $\mathrm{ABS}$ and PL peaks attributed to the difference in the dielectric medium surrounding the molecules (Table 1). 
With regard to $\phi_{\mathrm{PL}}^{\text {film }}$ measurements, the values obtained for $b$-PDI-A and $b$-PDI-O (89 and $87 \%$, respectively) are comparable to those measured in liquid solution. In contrast, for $b$-PDI-Tp, it is somewhat lower $\left(\phi_{\mathrm{PL}}{ }^{\text {film }}=61 \%\right)$ than the value in liquid solution $\left(\phi_{\mathrm{PL}}{ }^{\text {sol }}=78 \%\right)$, which points to the presence of molecular aggregation/interaction even at very low concentrations in the film. Indeed, according to theoretical calculations, a larger predisposition of $b$-PDI-Tp to form dimeric species is to be expected.

PL lifetime measurements for doped thin films also show differences in comparison to liquid solutions, as well as differences among the different compounds. For the $b$-PDI-Adoped film, the PL decay curve (see Figure S8) maintains a single exponential behavior, as in the liquid solution. The value obtained for $\tau_{\mathrm{PL}}{ }^{\text {film }}$ (5.6 ns) is only slightly larger than that in liquid solution $\left(\tau_{\mathrm{PL}}{ }^{\text {sol }}=5.1 \mathrm{~ns}\right)$. Meanwhile, the PL transients for the $b$-PDI-O and $b$-PDI-Tp-doped films (Figure S8) show a double exponential decay behavior, with $\tau_{\mathrm{PL}}{ }_{\mathrm{film}}=5.1$ and $4.2 \mathrm{~ns}$ for $b$-PDI-O and $b$-PDI-Tp, respectively. Note that for $b$-PDI$\mathrm{O}, \tau_{\mathrm{PL}}^{\text {film }}$ is very similar to the value obtained in toluene solution ( $4.9 \mathrm{~ns})$, while for $b$-PDI-Tp $\tau_{\mathrm{PL}}^{\text {film }}$ is shorter than that in solution $(5.1 \mathrm{~ns})$. The double exponential character and the time shortening observed for these two compounds evidence a certain degree of molecular interaction/aggregation, even for the very low dye concentrations used in these films, which are attributed to intermolecular interactions promoted by the bulky phenyl-containing groups introduced at the imide positions.

3.4.2. Amplified Spontaneous Emission. A property, for which the type of imide substituent of $b$-PDI has a clear impact, is the ASE, and particularly its photostability, as described below. The ASE spectra (recorded well above the pump intensity threshold) for the studied $b$-PDI doped films, consist of narrow peaks of around $6 \mathrm{~nm}$ width appearing at approximately $620 \mathrm{~nm}$, coinciding with the PL transition (01) (Figure $4 a$ ). This constitutes the usual behavior for PDI derivatives. $^{15,22}$

A remarkable result is an improved photostability observed for $b$-PDI-O and $b$-PDI-Tp, with respect to that of $b$-PDI-A. This is illustrated in Figure $4 b$, which displays the ASE intensity as a function of time and the number of pump pulses for the $b$-PDI-doped films. These experiments were carried out at a very large pump intensity $\left(I_{\text {pump }}=2500 \mathrm{~kW} \mathrm{~cm}^{-2}\right)$. This $I_{\text {pump }}$ is well above the $I_{\text {th }}{ }^{\text {ASE }}$ for all of them, allowing a comparison under similar conditions, given their similar $\alpha$, see Table 1. Quantitatively, the $\tau_{1 / 2}$ ASE values for the $b$-PDI-O and $b$-PDI-Tp-doped films (23 and $27 \mathrm{~min}$, respectively, which is a similar value for the two materials) are around three times larger than that of the $b$-PDI-A-doped film ( $9 \mathrm{~min}$, see Figure $4 b)$.

Generally speaking, understanding the physical processes responsible for dye photodegradation is non-trivial. Different mechanisms have been proposed in the literature for different dyes, ${ }^{43,44}$ although little has been said in connection with the chemical structure. ${ }^{45}$ With regard to PDIs, there have been a few studies on bay-unsubstituted PDIs, which attributed the photodegradation to two different mechanisms: type II photooxidation, under aerobic conditions, ${ }^{46,47}$ and photo-reduction, under anaerobic conditions; ${ }^{47}$ neglecting thermal photodegradation. ${ }^{13}$ Other photodegradation mechanisms have been proposed for systems other than PDIs. For example, photoionization after promotion to an excited electronic state, typically in polar media, direct bond fission under high excitation power, ${ }^{44}$ or photooxidative degradation proceeding through radical formation and subsequent chain reaction in polymers. $^{48}$

The larger photostability of $b$-PDI-O and $b$-PDI-Tp, relative to that of $b$-PDI-A, seems to be related to the type of substituents attached to their imide nitrogen atoms, given that this is the only difference among the various compounds. It should be noted though that the nodal character of the imide nitrogen atoms electronically uncouples the $b$-PDI core from the imide substituent. Therefore, type II photo-oxidation, photo-reduction, direct photoionization, or mechanisms involving ISC, triplets, or any other feature related to the energy level structure of the $b$-PDIs become unfeasible for explaining the different photostability behaviors of the various $b$-PDIs under study. A possible hypothesis is to consider the occurrence of a radical reaction at the imide substituent after a $\mathrm{C}-\mathrm{H}$ scission (see Scheme S1 in the Supporting Information). The latter would occur via photo-oxidation, assuming that, despite the nodal character, the excited core is able to transfer part of its energy to the imide substituents. The formation of this carbon-centered radical would lead preferentially to the decomposition of the substituent, and eventually to a nitrogenbased PDI radical. This would continue reacting and, might lead to chromophore decomposition. In this case, the ease of the reaction would be related to the stability of the alkyl/aryl radicals generated, which is inversely proportional to the bond dissociation energy $(D)$. Initially, $b$-PDI-A would yield the most stable radical, after losing the hydrogen atom located in the $\alpha$ position to the nitrogen, which is a tertiary radical ( $D$ for a $\mathrm{Me}_{3} \mathrm{C}-\mathrm{H}$ bond is $\left.95.8 \mathrm{kcal} \mathrm{mol}^{-1}\right) .^{49}$ In the case of $b$-PDI-O, a tertiary radical could be generated on the isopropyl group, but chain breaking, in this case, is less feasible because it will lead to the formation of a phenyl radical, which is less stable ( $D$ for a $\mathrm{Ph}-\mathrm{H}$ bond is $111 \mathrm{kcal} \mathrm{mol}^{-1}$ ). ${ }^{49}$ Finally, $b$-PDI-Tp would lead directly to a phenyl radical that is the least stable, thus assuring a better photostability for this PDI. This mechanism would explain similar differences reported for $u$ PDIs. ${ }^{12}$

To corroborate this point, we prepared four samples (neat PS, $b$-PDI-A dispersed in PS, $b$-PDI-O dispersed in PS, and $b$ PDI-Tp dispersed in PS) identical to the ones used for ASE characterization, and subjected them to pulsed laser irradiation for several hours. Then, we studied the films by MALDI-ToF mass spectrometry (Figure S12). MS analysis of the $b$-PDI-Adoped PS film after irradiation (Figures $\mathrm{S} 12 \mathrm{f}-\mathrm{h}$ ) showed peaks at $m / z 1059$ (which could correspond to the loss of a hexylheptyl chain from the parent PDI $m / z=1242$ ) and 1018 (the loss of a hexylheptyl-N-CO chain with the rearrangement of 1 hydrogen atom from the chain to the PDI residue). The study of the $b$-PDI-O-doped PS film after irradiation (Figures S12i,j) revealed clusters of peaks at $m / z 1182,1167$, 1151,1135 , and 1120 presumably corresponding with the loss of $\mathrm{CH}_{4}$ or $\mathrm{CH}_{3}$ groups from the parent PDI $(\mathrm{m} / z=1198)$ as it would be expected if radicals are centered on the isopropyl groups. These peaks overlap with those present in the neat PS film, however, if the MS spectra of $b$-PDI-O-doped PS and neat PS films are compared (Figure S12k), the former showed an increase in the number of peaks of the clusters, indicating the contribution of $b$-PDI-O degradation fragments. Peaks corresponding to the loss of diisopropylphenyl or diisopropylphenyl- $N$ groups were not detected. Finally, in the MS analysis of the $b$-PDI-Tp-doped PS film after irradiation (Figures $\mathrm{S} 12 \mathrm{l}, \mathrm{m})$, no peaks corresponding to the loss of phenyl or 
a

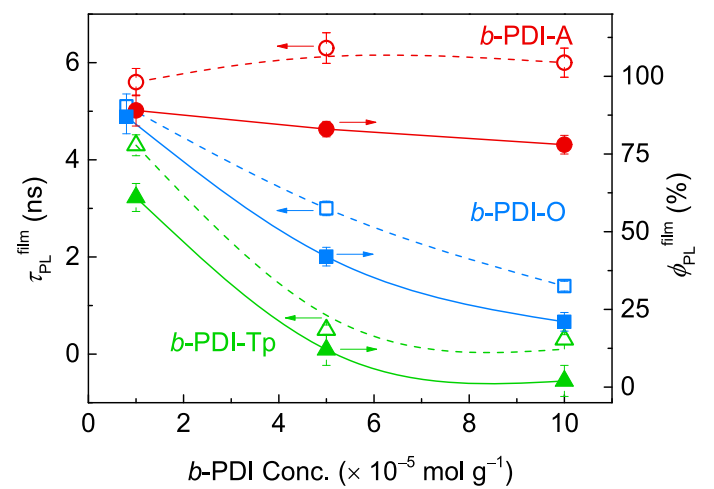

C

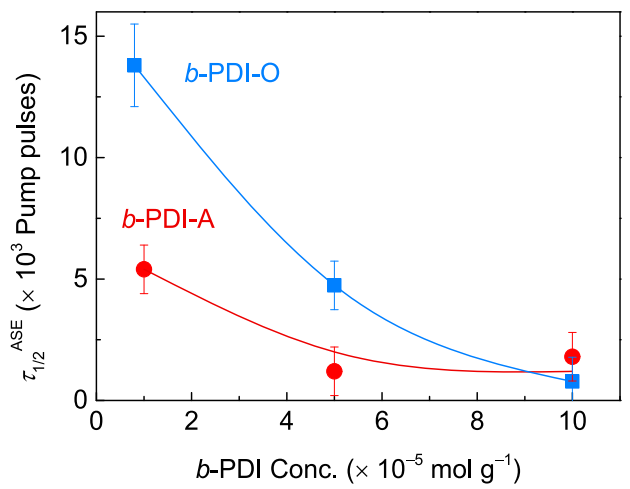

b

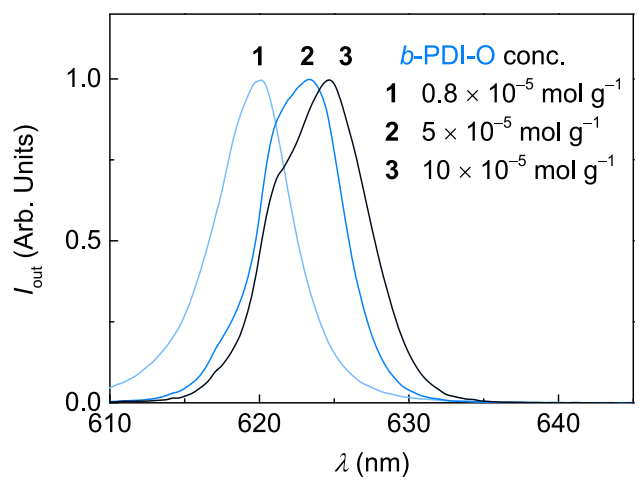

d

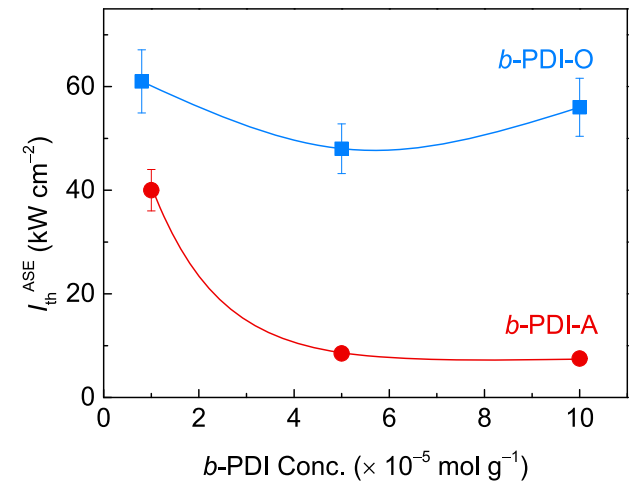

Figure 5. Concentration dependence. (a) Photoluminescence efficiency $\left(\phi_{\mathrm{PL}}\right.$ film , full symbols) and average photoluminescence lifetime $\left(\tau_{\mathrm{PL}}\right.$ film, open symbols) in terms of the dye concentration for PS films doped with $b$-PDI-O (blue squares), $b$-PDI-Tp (green triangles), and $b$-PDI-A (red circles). Solid and dashed lines are guides to the eye. (b) Normalized ASE spectra for PS films doped with $b$-PDI-O at concentrations of $0.8 \times 10^{-5}$, $5 \times 10^{-5}$, and $10 \times 10^{-5} \mathrm{~mol} \mathrm{~g}^{-1}$. (c) ASE half-life $\left(\tau_{1 / 2}\right.$ ASE $)$ versus dye concentration for PS films doped with $b$-PDI-O (blue squares) and $b$-PDI-A (red circles) under uninterrupted excitation at $2500 \mathrm{~kW} \mathrm{~cm}^{-2}$. Lines are guides to the eye. (d) ASE threshold ( $I_{\text {th }}{ }^{\text {ASE }}$ ) as a function of dye concentration for PS films doped with $b$-PDI-O (blue squares) and $b$-PDI-A (red circles). Lines are guides to the eye.

terphenyl- $N$ groups from the parent PDI $(m / z=1334)$ could be detected, only a peak at $m / z 1105$, attributable to the loss of a terphenyl group, is hardly visible.

With respect to the ASE thresholds, determined from plots of the emission linewidth and the output intensity as a function of $I_{\text {pump, }}$ such as those represented in Figure $4 c$, the performance of $b$-PDI-A and $b$-PDI-O are rather similar (slightly better for $b$-PDI-A), with $I_{\text {th }}{ }^{\text {ASE }}$ values of 40 and 60 $\mathrm{kW} \mathrm{cm}{ }^{-2}$, respectively. On the other hand, it is larger for $b$ PDI-Tp $\left(I_{\text {th }}{ }^{\text {ASE }}=230 \mathrm{~kW} \mathrm{~cm}{ }^{-2}\right)$. The differences among the various $b$-PDIs can be explained in terms of their $\phi_{\mathrm{PL}}{ }^{\text {film }}$, which is larger for $b$-PDI-A and $b$-PDI-O, and lower for $b$-PDI-Tp, as previously discussed.

3.4.3. Transient Absorption. The film transient absorption (TA) spectra manifest the same features for the different $b$ PDIs (see Figure $4 \mathrm{~d}$ for $b$-PDI-O and Figure S13 for $b$-PDI-A and $b$-PDI-Tp). All spectra show the following features: (1) a negative peak at around $560 \mathrm{~nm}$, which corresponds to ground-state bleaching (GSB) from the first ABS (0-0) peak, (2) a negative peak at around $615 \mathrm{~nm}$ attributed to stimulated emission (SE) from the first PL vibronic (0-1) peak, and (3) a broad positive band from approximately 640 to $950 \mathrm{~nm}$, probably further, which corresponds to excited-state absorption (ESA). The ESA band reflects the absorption of the initially created singlet population, as their lifetimes coincide with SE and GSB lifetimes. The ESA band seems to overlap with the SE band, which might be a factor limiting the ASE performance of the $b$-PDIs. The SE cross-section $\left(\sigma_{\mathrm{SE}}\right)$ for the three $b$-PDIs presents a similar value of around $8 \times 10^{-17} \mathrm{~cm}^{2}$. Then, the differences observed in $I_{\text {th }}{ }^{\text {ASE }}$ can be definitively attributed to the differences in $\phi_{\mathrm{PL}}{ }^{\text {film }}$.

3.5. Dye Concentration Dependence. The differences observed in the optical properties of these $b$-PDIs become more pronounced when analyzing the performance of dyedoped PS films at higher dye contents. This is evidenced by studying films doped with $1 \times 10^{-5}\left(0.8 \times 10^{-5}\right.$ for $b$-PDI-O $)$, $5 \times 10^{-5}$, and $10 \times 10^{-5} \mathrm{~mol} \mathrm{~g}^{-1}$ (approximately equivalent to 1,6 , and 11 wt $\%$, respectively).

3.5.1. Absorbance and Photoluminescence. The ABS spectra are practically not affected by the increase in the dye content, maintaining the spectral shape of the highly diluted films analyzed in the previous section. The ABS peaks appear at the same wavelengths and show the same relative intensities. For each $b$-PDI, the total ABS increases proportionally to the concentration (see Figure S10).

In contrast, the PL properties are significantly affected by the increase in the dye content, at different degrees for each $b$-PDI. This is clearly illustrated by film $\phi_{\mathrm{PL}}$ film data (see Figure 5a and Table 1). For the three compounds, the $\phi_{\mathrm{PL}}{ }^{\text {film }}$ decreases with increasing doping rate, but much more rapidly for $b$-PDI-O and $b$-PDI-Tp. The decrease of $\phi_{\mathrm{PL}}{ }^{\text {film }}$ is indicative of molecular aggregation/interaction, which appears to be more significant in $b$-PDI-Tp, as suggested by the theoretical calculations. The decrease in $\phi_{\mathrm{PL}}{ }^{\text {film }}$ is also reflected in their PL spectra (Figure S11). The total PL intensity (normalized by dividing by film absorption at the pump wavelength) decreases 
as the concentration increases, slightly in $b$-PDI-A, and more significantly for the other two compounds. With regard to the PL spectral shape, it is practically not affected in $b$-PDI-A and b-PDI-O: small red-shifts in the PL peak wavelengths, and a small change in the proportion of the intensities of the PL peaks $(0-0)$ and $(0-1)$ (from 1.9 to 1.7 , for the explored concentration range). On the other hand, significant changes are observed for $b$-PDI-Tp, particularly in the proportion of the intensities of the PL peaks (0-0) and (0-1) (it varies from 1.8 to 0.3 ). Actually, this change is related to the appearance of a third peak on the red side of the spectrum, at around $670 \mathrm{~nm}$, which might be due to an excimer species, as it occurs in $u$ PDIs. ${ }^{12,15}$ Indeed, it agrees as well with the lack of changes observed in the ABS spectra.

The change of the dye-doping rate also affects the PL transients (see Figure S8), and as it occurs for the $\phi_{\mathrm{PL}}$ film, to a different extent for each $b$-PDI. The average PL lifetimes, $\tau_{\mathrm{PL}}{ }^{\text {film }}$, obtained from the fits of the PL transients, are plotted in Figure 5a. As expected, they follow trends similar to those of their $\phi_{\mathrm{PL}}{ }^{\text {film }}$ values. In the case of $b$-PDI-A, the PL transients preserve the single exponential decay character shown in the liquid solutions and the highly diluted films, with only a slightly larger lifetime, $\tau_{\mathrm{PL}}{ }^{\text {film }} \approx 6$ ns (Figure 5a and Table 1 ). For $b$ PDI-O and $b$-PDI-Tp, the PL transients follow double or triple exponential functions (Figure S8). The $\tau_{\mathrm{PL}}{ }^{\text {film }}$ values for these two $b$-PDIs suffer a severe drop as the doping load increases (Figure 5a and Table 1), with an onset at lower doping loads for $b$-PDI-Tp. The multi-exponential character together with the time shortening observed for $b$-PDI-O and $b$-PDI-Tp clearly indicate molecular aggregation/interaction in these films. Particularly, in the case of $b$-PDI-Tp, this aggregation/ interaction generates excimer species, which is endorsed by streak camera measurements for the film doped with the largest concentration (see details in the Supporting Information, Figure S13) and the observed effects in the ABS and PL spectra with the concentration described previously. The PL spectrum presented in Figure S14 for 50 ps coincides with the single-molecule spectrum and the spectrum recorded for 1500 ps is attributed to the aggregates. By comparing both emission spectra, one can estimate dimer association energy $(<20 \mathrm{meV})$ and type of dimers. In this case, the small energetic difference and pronounced change of the vibronic structure of the aggregate spectrum may suggest the formation of $\mathrm{H}$-aggregate dimers. ${ }^{50}$ From the deconvolution of these time-resolved PL data, an energy transfer lifetime of $0.4 \mathrm{~ns}$ was estimated for transfer from the single-molecule excited state toward the dimer excited state.

3.5.2. Amplified Spontaneous Emission. The previous differences in the dye concentration dependence are reflected in the ASE performances of these $b$-PDIs. The evolution of various ASE properties (spectra, photostability, and thresholds) upon the increase in the dye concentration is analyzed in Figure $5 b-d$. The increase of the doping load produces a similar red-shift on the ASE spectra for the different $b$-PDIs (see Table 1). The progressive displacement of the peak position is illustrated in Figure $5 b$ for $b$-PDI-O-doped films. The behavior is similar to that previously reported for $b$-PDIA. ${ }^{15}$

The concentration dependence of the ASE photostability half-life, $\tau_{1 / 2}{ }^{\text {ASE }}$, for $b$-PDI-A and $b$-PDI-O-doped films is analyzed in Figure $5 c$ (see also Table 1 ). These $\tau_{1 / 2}{ }^{\text {ASE }}$ values were determined by pumping the films uninterruptedly with a fluence of $2500 \mathrm{~kW} \mathrm{~cm}^{-2}$. For both $b$-PDIs, $\tau_{1 / 2}$ ASE suffers a severe drop with the increase in the concentration, with a steeper slope in the case of $b$-PDI-O. As discussed in the previous section, $b$-PDI-O is three times more photostable than $b$-PDI-A for highly diluted films. However, this difference tends to be reduced when the concentration is increased mainly due to the increase in the absorption of the film, but other factors such as molecular aggregation/interaction might also play a role. Thus, at the highest concentrations studied here, the $\tau_{1 / 2}{ }^{\text {ASE }}$ values for both $b$-PDIs are comparable.

In the case of the ASE thresholds, $I_{\text {th }}{ }^{A S E}$, a different concentration dependence was observed for each $b$-PDI (Table $1)$. For $b$-PDI-O, the $I_{\text {th }}{ }^{\text {ASE }}$ shows an initial mild descent, followed by a slow increase (Figure $5 \mathrm{~d}$ ), the minimum value being $I_{\mathrm{th}}{ }^{\mathrm{ASE}}=50 \mathrm{~kW} \mathrm{~cm}{ }^{-2}$. For $b$-PDI-A, $I_{\mathrm{th}}{ }^{\mathrm{ASE}}$ shows a much pronounced initial descent, followed by a concentration range, in which the $I_{\mathrm{th}}{ }^{\mathrm{ASE}}$ value is maintained (Figure 5d). In this case, the lowest threshold is $I_{\text {th }}{ }^{\text {ASE }}=7.5 \mathrm{~kW} \mathrm{~cm}^{-2}$. Finally, in the case of $b$-PDI-Tp, $I_{\text {th }}{ }^{\text {ASE }}$ increases with concentration for the whole range (Table 1 ), and the minimum value is $I_{\text {th }}{ }^{\text {ASE }}=230$ $\mathrm{kW} \mathrm{cm}{ }^{-2}$, the largest among the three compounds. It should be noted that in this case, no ASE was observed for the largest concentration analyzed.

3.5.3. Transient Absorption. TA measurements provide a deeper understanding of the concentration quenching mechanism, which results in a significant decrease in the PL efficiency and, consequently, in an increase of the ASE thresholds. For different doping loads, the TA spectra maintain the same features as previously observed for highly diluted doped films (see Figure S13). Even, similar $\sigma_{\mathrm{SE}}$ values were found for the different concentrations, between $8 \times 10^{-17}$ and $6 \times 10^{-17} \mathrm{~cm}^{2}$ in all cases (Table S2). However, the transient dynamics show clear concentration dependence (see Figure 6).

For highly diluted doped films, similar dynamics are found for the different $b$-PDIs. These dynamics show a governing long decay component $(\approx 2 \mathrm{~ns}$, exact values in Table S2) and secondary components with modest contributions $(\approx 1$ to 100 ps). As a general trend, the dynamics shorten when the doping load is increased. There are two contributions to this shortening. First, the direct shortening of the governing decay: in the case of $b$-PDI-A, it is a moderate shortening with the dominant component passing from 1.6 to $1.2 \mathrm{~ns}$; for $b$ PDI-O, the shortening is more accentuated passing from 2.3 to $0.4 \mathrm{~ns}$; and for $b$-PDI-Tp, it is very significant passing from 2.2 to $0.05 \mathrm{~ns}$. Second, the contributions of the secondary components to the dynamics increase. Certainly, these time shortening and multi-exponential character reflect the presence of non-emissive trapping centers, which lead to non-radiative deactivation of the excited-state population.

This phenomenon has a direct impact on the time that the material maintains the excited state available to contribute to the SE. A shorter time makes the generation of a population inversion in the media more difficult, which leads to an increase of the ASE threshold. This quenching mechanism opposes the reduction of the ASE threshold associated with the expected concentration increase (more molecules participating in the ASE process). Then, the actual $I_{\text {th }}{ }^{\text {ASE }}$ would be determined through the balance between the number of molecules participating in the ASE process and the PL quenching mechanism, both being directly related to the concentration increase. 


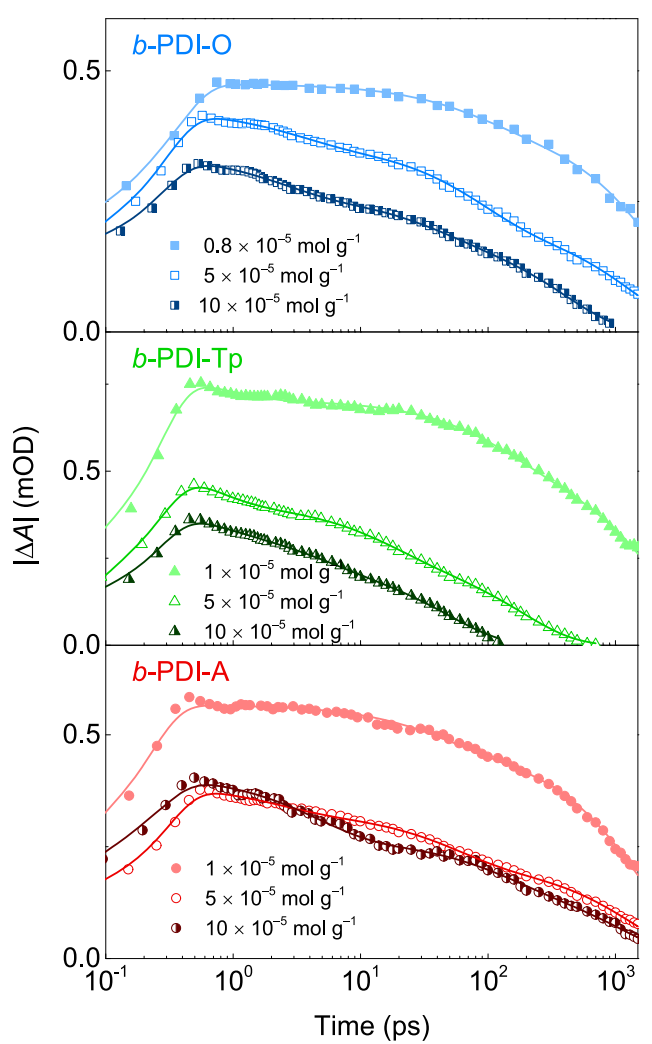

Figure 6. Transient absorption dynamics at stimulated emission maxima for $b$-PDI-O (blue squares, top panel), $b$-PDI-Tp (green triangles, central panel), and $b$-PDI-A (red circles, bottom panel). Full, open, and half-filled symbols correspond respectively to $1 \times 10^{-5}$ $\left(0.8 \times 10^{-5}\right.$ for $b$-PDI-O $), 5 \times 10^{-5}$, and $10 \times 10^{-5} \mathrm{~mol} \mathrm{~g}^{-1}$. Solid lines correspond to double or triple exponential fits to the data.

\section{CONCLUSIONS}

Two new $b$-PDIs synthesized here, $b$-PDI-O and $b$-PDI-Tp, bearing phenyl-type imide substituents, and the previously reported $b$-PDI-A, bearing aliphatic-type imide substituents, have been compared in terms of their steady and transient optical properties (ABS, PL, emission efficiency, PL lifetimes, and TA) and ASE performance (threshold and photostability half-life). For each $b$-PDI, PS films doped with increasing concentrations $\left(0.8 \times 10^{-5}, 5 \times 10^{-5}\right.$, and $\left.10 \times 10^{-5} \mathrm{~mol} \mathrm{~g}^{-1}\right)$ have been analyzed seeking differences between $b$-PDIs; first, when no molecular aggregation/interaction is present, and second, with respect to their dye concentration dependence. These results have also been supported by DFT and TD-DFT calculations.

The ASE photostability of the molecules is directly affected by the imide substituent. For films in which the molecular aggregation/interaction can be disregarded, $b$-PDIs with phenyl-based substituents last approximately three times more than those with aliphatic chains substituents. However, these differences tend to disappear when the concentration increases. Regarding the ASE threshold, the $b$-PDI imide substituents show an indirect but very significant impact on it through concentration quenching. This is evidenced by the similarly stimulated emission cross-sections found for the different $b$-PDIs at different concentrations, meaning that the emissive properties of the individual molecule remain unaffected. Nonetheless, DFT calculations of $b$-PDI dimers, $\mathrm{PL}$ quantum yields, and PL lifetimes suggest different concentration quenching degrees for each $b$-PDI, which translates into the ASE threshold differences observed. Lower ASE thresholds are obtained with the use of aliphatic-type substituents at imide positions, which is found to prevent more effectively the molecular aggregation/interaction than phenylbased substituents. Therefore, future designs of substituents at imide positions for successful $b$-PDI-based lasers should target simultaneous prevention of dye concentration quenching and maintainance of high resistance to photodegradation.

\section{ASSOCIATED CONTENT}

\section{Supporting Information}

The Supporting Information is available free of charge at https://pubs.acs.org/doi/10.1021/acs.jpcc.1c00833.

${ }^{1} \mathrm{H}$ and ${ }^{13} \mathrm{C}$ NMR spectra of $b$-PDI-O and $b$-PDI-Tp in $\mathrm{CDCl}_{3}$ solution; MALDI-TOF MS spectra of $b$-PDI-O and $b$-PDI-Tp; optimized structures calculated for supramolecular dimers of $b$-PDI-A and $b$-PDI-O; extinction coefficient and photoluminescence spectra for toluene solutions of $b$-PDI-A, $b$-PDI-O, and $b$-PDI$\mathrm{Tp}$; frontier molecular orbitals calculated for $b$-PDI-A, $b$ PDI-O, and $b$-PDI-Tp; PL transients at $575 \mathrm{~nm}$ of $b$ PDIs in toluene solutions and dispersed in PS films; fluorescence efficiency of $b$-PDIs in toluene solution; absorption coefficient and normalized PL spectra of PS films doped with $b$-PDIs; scheme with proposed $\mathrm{C}-\mathrm{H}$ scission reactions in $b$-PDIs; MALDI-ToF MS spectra of films after and before photodegradation; transient absorption spectra for PS films doped with $b$-PDIs; time-resolved PL measurements of PS films doped with $b$-PDI-Tp with ps resolution; a table with the lowestlying singlet excited states calculated for $b$-PDIs; and table with the photophysical parameters for $b$-PDIs in doped PS films (PDF)

\section{AUTHOR INFORMATION}

\section{Corresponding Authors}

Rafael Muñoz-Mármol - Departamento de Física Aplicada and Instituto Universitario de Materiales de Alicante, Universidad de Alicante, 03080 Alicante, Spain; ○ orcid.org/0000-0002-7022-0215; Email: rafa.marmol@ ua.es

Fernando Fenández-Lázaro - Área de Química Orgánica, Instituto de Bioingeniería, Universidad Miguel Hernández, 03202 Elche, Spain; 이이이.org/0000-0002-4598-6024; Email: fdofdez@umh.es

María A. Díaz-García - Departamento de Física Aplicada and Instituto Universitario de Materiales de Alicante, Universidad de Alicante, 03080 Alicante, Spain; 이이.org/00000001-7025-5699; Email: maria.diaz@ua.es

\section{Authors}

Pedro G. Boj - Departamento de Óptica, Farmacología y Anatomía and Instituto Universitario de Materiales de Alicante, Universidad de Alicante, 03080 Alicante, Spain

José M. Villalvilla - Departamento de Física Aplicada and Instituto Universitario de Materiales de Alicante, Universidad de Alicante, 03080 Alicante, Spain

José A. Quintana - Departamento de Óptica, Farmacología y Anatomía and Instituto Universitario de Materiales de Alicante, Universidad de Alicante, 03080 Alicante, Spain 
Nathalie Zink-Lorre - Área de Química Orgánica, Instituto de Bioingeniería, Universidad Miguel Hernández, 03202 Elche, Spain; 이이이.org/0000-0003-3081-995X

Ángela Sastre-Santos - Area de Química Orgánica, Instituto de Bioingeniería, Universidad Miguel Hernández, 03202 Elche, Spain; 이이이.org/0000-0002-8835-2486

Juan Aragó - Instituto de Ciencia Molecular, Universidad de Valencia, 46980 Paterna, Spain; 이이.org/0000-00020415-9946

Enrique Ortí - Instituto de Ciencia Molecular, Universidad de Valencia, 46980 Paterna, Spain; (1) orcid.org/0000-00019544-8286

Paulius Baronas - Institute of Photonics and Nanotechnology, Vilnius University, LT-10257 Vilnius, Lithuania

Džiugas Litvinas - Institute of Photonics and Nanotechnology, Vilnius University, LT-10257 Vilnius, Lithuania

Saulius Juršènas - Institute of Photonics and Nanotechnology, Vilnius University, LT-10257 Vilnius, Lithuania

Complete contact information is available at:

https://pubs.acs.org/10.1021/acs.jpcc.1c00833

\section{Notes}

The authors declare no competing financial interest.

\section{ACKNOWLEDGMENTS}

The authors thank the Spanish Ministry of Economy and Competitiveness MINECO and the European Social Funds (project MAT2015-66586-R and FPI fellowship BES-2016077681), the Ministry of Science and Innovation (MICINN) and the European FEDER funds (CTQ2016-77039-R, PGC2018-099568-B-I00, and PID2019-109200GB-I00, and Unidad de Excelencia María de Maeztu CEX2019-000919-M), and the Generalitat Valenciana (PROMETEO/2020/077 and SEJI/2018/035). J.A. acknowledges the MICINN for the "Ramón-y-Cajal” Fellowship (RyC-2017-23500).

\section{REFERENCES}

(1) Kuehne, A. J. C.; Gather, M. C. Organic Lasers: Recent Developments on Materials, Device Geometries, and Fabrication Techniques. Chem. Rev. 2016, 116, 12823-12864.

(2) Grivas, C. Optically Pumped Planar Waveguide Lasers: Part II: Gain Media, Laser Systems, and Applications. Prog. Quantum Electron. 2016, 45-46, 3-160.

(3) Forrest, S. R. The Path to Ubiquitous and Low-Cost Organic Electronic Appliances on Plastic. Nature 2004, 428, 911-918.

(4) Zhu, C.; Liu, L.; Yang, Q.; Lv, F.; Wang, S. Water-Soluble Conjugated Polymers for Imaging, Diagnosis, and Therapy. Chem. Rev. 2012, 112, 4687-4735.

(5) Retolaza, A.; Martinez-Perdiguero, J.; Merino, S.; Morales-Vidal, M.; Boj, P. G.; Quintana, J. A.; Villalvilla, J. M.; Díaz-García, M. A. Organic Distributed Feedback Laser for Label-Free Biosensing of ErbB2 Protein Biomarker. Sens. Actuators, B 2016, 223, 261-265.

(6) Morales-Vidal, M.; Boj, P. G.; Quintana, J. A.; Villalvilla, J. M.; Retolaza, A.; Merino, S.; Díaz-García, M. A. Distributed Feedback Lasers Based on Perylenediimide Dyes for Label-Free Refractive Index Sensing. Sens. Actuators, B 2015, 220, 1368-1375.

(7) Nowak-Król, A.; Würthner, F. Progress in the Synthesis of Perylene Bisimide Dyes. Org. Chem. Front. 2019, 6, 1272-1318.

(8) Sadrai, M.; Bird, G. R. A New Laser Dye with Potential for High Stability and a Broad Band of Lasing Action: Perylene-3,4,9,10Tetracarboxylic Acid-Bis-N,N'(2',6' Xylidyl)Diimide. Opt. Commun. 1984, 51, 62-64.

(9) Löhmannsröben, H.-G.; Langhals, H. Laser Performance of Perylenebis (Dicarboximide) Dyes with Long Secondary Alkyl Chains. Appl. Phys. B 1989, 48, 449-452.
(10) Reisfeld, R.; Brusilovsky, D.; Eyal, M.; Miron, E.; Burshtein, Z.; Ivri, J. Perylene Dye In A Composite Sol-Gel Glass - A New SolidState Tunable Laser In The Visible Range. Proc. SPIE 1989, 1182, 230-239.

(11) García-Moreno, I.; Costela, A.; Pintado-Sierra, M.; Martín, V.; Sastre, R. Enhanced Laser Action of Perylene-Red Doped Polymeric Materials. Opt. Express 2009, 17, 12777.

(12) Ramírez, M. G.; Morales-Vidal, M.; Navarro-Fuster, V.; Boj, P. G.; Quintana, J. A.; Villalvilla, J. M.; Retolaza, A.; Merino, S.; DíazGarcía, M. A. Improved Performance of Perylenediimide-Based Lasers. J. Mater. Chem. C 2013, 1, 1182-1191.

(13) Cerdán, L.; Costela, A.; Durán-Sampedro, G.; García-Moreno, I.; Calle, M.; Juan-y-Seva, M.; de Abajo, J.; Turnbull, G. A. New Perylene-Doped Polymeric Thin Films for Efficient and Long-Lasting Lasers. J. Mater. Chem. 2012, 22, 8938-8947.

(14) Calzado, E. M.; Villalvilla, J. M.; Boj, P. G.; Quintana, J. A.; Gómez, R.; Segura, J. L.; Díaz García, M. A. Amplified Spontaneous Emission in Polymer Films Doped with a Perylenediimide Derivative. Appl. Opt. 2007, 46, 3836-3842.

(15) Muñoz-Mármol, R.; Zink-Lorre, N.; Villalvilla, J. M.; Boj, P. G.; Quintana, J. A.; Vázquez, C.; Anderson, A.; Gordon, M. J.; SastreSantos, A.; Fernández-Lázaro, F.; Díaz-García, M. A. Influence of Blending Ratio and Polymer Matrix on the Lasing Properties of Perylenediimide Dyes. J. Phys. Chem. C 2018, 122, 24896-24906.

(16) Kreiza, G.; Baronas, P.; Radiunas, E.; Adomenas, P.; Adomeniene, O.; Kazlauskas, K.; Ribierre, J.-C.; Adachi, C.; Juršenas, S. Bifluorene Single Crystals with Extremely Low-Threshold Amplified Spontaneous Emission. Adv. Opt. Mater. 2017, 5, No. 1600823.

(17) Baronas, P.; Kazlauskas, K.; Kreiza, G.; Jankauskas, V.; Tomkeviciene, A.; Simokaitiene, J.; Grigalevicius, S.; Grazulevicius, J. V.; Juršènas, S. Differently Linked Fluorene-Carbazole Triads for Light Amplification. Dyes Pigm. 2015, 123, 370-379.

(18) Calzado, E. M.; Villalvilla, J. M.; Boj, P. G.; Quintana, J. A.; Gómez, R.; Segura, J. L.; Díaz-García, M. A. Effect of Structural Modifications in the Spectral and Laser Properties of Perylenediimide Derivatives. J. Phys. Chem. C 2007, 111, 13595-13605.

(19) Díaz-García, M. A.; Calzado, E. M.; Villalvilla, J. M.; Boj, P. G.; Quintana, J. A.; Céspedes-Guirao, F. J.; Fernández-Lázaro, F.; SastreSantos, A. Effect of Structural Modifications in the Laser Properties of Polymer Films Doped with Perylenebisimide Derivatives. Synth. Met. 2009, 159, 2293-2295.

(20) Miasojedovas, A.; Kazlauskas, K.; Armonaite, G.; Sivamurugan, V.; Valiyaveettil, S.; Grazulevicius, J. V.; Juršènas, S. Concentration Effects on Emission of Bay-Substituted Perylene Diimide Derivatives in a Polymer Matrix. Dyes Pigm. 2012, 92, 1285-1291.

(21) Lin, M.-J.; Jiménez, AJ.; Burschka, C.; Würthner, F. BaySubstituted Perylene Bisimide Dye with an Undistorted Planar Scaffold and Outstanding Solid State Fluorescence Properties. Chem. Commun. 2012, 48, 12050-12052.

(22) Ramírez, M. G.; Pla, S.; Boj, P. G.; Villalvilla, J. M.; Quintana, J. A.; Díaz-García, M. A.; Fernández-Lázaro, F.; Sastre-Santos, Á. 1,7Bay-Substituted Perylenediimide Derivative with Outstanding Laser Performance. Adv. Opt. Mater. 2013, 1, 933-938.

(23) Jiménez, Á. J.; Lin, M. J.; Burschka, C.; Becker, J.; Settels, V.; Engels, B.; Würthner, F. Structure-Property Relationships for 1,7Diphenoxy-Perylene Bisimides in Solution and in the Solid State. Chem. Sci. 2014, 5, 608-619.

(24) Signoretto, M.; Zink-Lorre, N.; Suarez, I.; Font-Sanchis, E.; Sastre-Santos, Á.; Chirvony, V. S.; Fernandez-La zaro, F.; MartínezPastor, J. P. Efficient Optical Amplification in a Sandwich-Type Active-Passive Polymer Waveguide Containing Perylenediimides. ACS Photonics 2017, 4, 114-120.

(25) Lee, C.; Yang, W.; Parr, R. G. Development of the ColleSalvetti Correlation-Energy Formula into a Functional of the Electron Density. Phys. Rev. B 1988, 37, 785-789.

(26) Becke, A. D. Density-Functional Thermochemistry. III. The Role of Exact Exchange. J. Chem. Phys. 1993, 98, 5648-5652. 
(27) Grimme, S.; Antony, J.; Ehrlich, S.; Krieg, H. A Consistent and Accurate $\mathrm{Ab}$ Initio Parametrization of Density Functional Dispersion Correction (DFT-D) for the 94 Elements H-Pu. J. Chem. Phys. 2010, 132, No. 154104.

(28) Francl, M. M.; Pietro, W. J.; Hehre, W. J.; Binkley, J. S.; Gordon, M. S.; DeFrees, D. J.; Pople, J. A. Self-Consistent Molecular Orbital Methods. XXIII. A Polarization-Type Basis Set for SecondRow Elements. J. Chem. Phys. 1982, 77, 3654-3665.

(29) Frisch, M. J.; Trucks, G. W.; Schlegel, H. E.; Scuseria, G. E.; Robb, M. A.; Cheeseman, J. R.; Scalmani, G.; Barone, V.; Petersson, G. A.; Nakatsuji et al. Gaussian 16, Revision A.1; Gaussian Inc.: Wallingford, CT, 2016.

(30) Casida, M. E.; Jamorski, C.; Casida, K. C.; Salahub, D. R. Molecular Excitation Energies to High-Lying Bound States from Time-Dependent Density-Functional Response Theory: Characterization and Correction of the Time-Dependent Local Density Approximation Ionization Threshold. J. Chem. Phys. 1998, 108, 4439-4449.

(31) Jamorski, C.; Casida, M. E.; Salahub, D. R. Dynamic Polarizabilities and Excitation Spectra from a Molecular Implementation of Time-Dependent Density-Functional Response Theory: N2 as a Case Study. J. Chem. Phys. 1996, 104, 5134-5147.

(32) Petersilka, M.; Gossmann, U. J.; Gross, E. K. U. Excitation Energies from Time-Dependent Density-Functional Theory. Phys. Rev. Lett. 1996, 76, 1212-1215.

(33) Zhurko, G. A. ChemCraft: Graphical Program for Visualization of Quantum Chemistry Computations, Ivanovo, Russia, http://www. chemcraftprog.com 2009.

(34) Bannwarth, C.; Ehlert, S.; Grimme, S. GFN2-XTB - An Accurate and Broadly Parametrized Self-Consistent Tight-Binding Quantum Chemical Method with Multipole Electrostatics and Density-Dependent Dispersion Contributions. J. Chem. Theory Comput. 2019, 15, 1652-1671.

(35) Grimme, S.; Bannwarth, C.; Shushkov, P. A Robust and Accurate Tight-Binding Quantum Chemical Method for Structures, Vibrational Frequencies, and Noncovalent Interactions of Large Molecular Systems Parametrized for All Spd-Block Elements $(Z=1$ 86). J. Chem. Theory Comput. 2017, 13, 1989-2009.

(36) Bonal, V.; Quintana, J. A.; Muñoz-Mármol, R.; Villalvilla, J. M.; Boj, P. G.; Díaz-García, M. A. Sub-400 nm Film Thickness Determination from Transmission Spectra in Organic Distributed Feedback Lasers Fabrication. Thin Solid Films 2019, 692, No. 137580.

(37) Williams, A. T. R.; Winfield, S. A.; Miller, J. N. Relative Fluorescence Quantum Yields Using a Computer-Controlled Luminescence Spectrometer. Analyst 1983, 108, 1067-1071.

(38) Langhals, H.; Karolin, J.; Johansson, L. B. Spectroscopic Properties of New and Convenient Standards for Measuring Fluorescence Quantum Yields. J. Chem. Soc., Faraday Trans. 1998, 94, 2919-2922.

(39) Fischer, M.; Georges, J. Fluorescence Quantum Yield of Rhodamine $6 \mathrm{G}$ in Ethanol as a Function of Concentration Using Thermal Lens Spectrometry. Chem. Phys. Lett. 1996, 260, 115-118.

(40) Lakowicz, J. R. Principles of Fluorescence Spectroscopy; Springer US: New York, USA, 2006.

(41) Morales-Vidal, M.; Boj, P. G.; Villalvilla, J. M.; Quintana, J. A.; Yan, Q.; Lin, N.-T.; Zhu, X.; Ruangsupapichat, N.; Casado, J.; Tsuji, H.; Nakamura, E.; Díaz-García, M. A. Carbon-Bridged Oligo(pPhenylenevinylene)s for Photostable and Broadly Tunable, SolutionProcessable Thin Film Organic Laser. Nat. Commun. 2015, 6, No. 8458.

(42) Lanzani, G. The Photophysics behind Photovoltaics and Photonics; WILEY-VCH Verlag \& Co. KKGaA: Weinheim, Germany, 2012.

(43) Ray, A. K.; Kumar, S.; Mayekar, N. V.; Sinha, S.; Kundu, S.; Chattopadhyay, S.; Dasgupta, K. Role of the Stimulated-Emission Rate in the Photostability of Solid-State Dye Lasers. Appl. Opt. 2005, 44, 7814-7822.

(44) Demchenko, A. P. Photobleaching of Organic Fluorophores: Quantitative Characterization, Mechanisms, Protection. Methods Appl. Fluoresc. 2020, 8, No. 022001.
(45) Oyama, Y.; Mamada, M.; Shukla, A.; Moore, E. G.; Lo, S. C.; Namdas, E. B.; Adachi, C. Design Strategy for Robust Organic Semiconductor Laser Dyes. ACS Mater. Lett. 2020, 2, 161-167.

(46) Seybold, G.; Wagenblast, G. New Perylene and Violanthrone Dyestuffs for Fluorescent Collectors. Dyes Pigm. 1989, 11, 303-317.

(47) Tanaka, N.; Barashkov, N.; Heath, J.; Sisk, W. N. Photodegradation of Polymer-Dispersed Perylene Di-Imide Dyes. Appl. Opt. 2006, 45, 3846-3851.

(48) Yousif, E.; Haddad, R. Photodegradation and Photostabilization of Polymers, Especially Polystyrene: Review. SpringerPlus 2013, 2, No. 398.

(49) Smith, M. B.; March, J. March's Advanced Organic Chemistry: Reactions, Mechanisms, and Structure; Wiley-VCH: Weinheim, Germany, 2000.

(50) Hestand, N. J.; Spano, F. C. Expanded Theory of H-and JMolecular Aggregates: The Effects of Vibronic Coupling and Intermolecular Charge Transfer. Chem. Rev. 2018, 118, 7069-70163. 